\title{
EFISIENSI PENGELUARAN PEMERINTAH BIDANG PENDIDIKAN DI INDONESIA (DATA ENVELOPMENT ANALYSIS)
}

\author{
Tomi Mandala Putra ${ }^{1}$ Merri Anitasari ${ }^{2}$ \\ ${ }^{1}$ Jurusan Ekonomi Pembangunan Fakultas Ekonomi dan Bisnis Universitas Bengkulu \\ Email:tomi123@gmail.com \\ ${ }^{1}$ Jurusan Ekonomi Pembangunan Fakultas Ekonomi dan Bisnis Universitas Bengkulu \\ Email: merrianitasari@unib.ac.id
}

\begin{abstract}
This study aims to determine the Level of Efficiency in Education Expenditures in 34 provinces in Indonesia. The type of data used in this study is the cross-section data for 2017. The use of budget input as an input variable and student-teacher ratio (RGM) as an output variable. This study uses descriptive analysis with analysis of Data Envelopment Analysis using the assumption of the Return to Scale (VRS) variable and the model used for input (input-oriented) input. The results of this study indicate that the general facts of large provinces in Indonesia are still very few that reach the level of efficiency in technical costs. Already 3 provinces have achieved efficiently. This proves there is still waste in education spending suggestions that can be submitted in this study about the local government to evaluate the use of education which must be adjusted to the number of teacher and student ratios in each region so there is no need to waste and local government can improve.
\end{abstract}

Keywords: $\quad$ Efficiency, Education Expenditures, Data Envelopment Analysis, Cost Technical

\section{PENDAHULUAN}

Pembangunan ekonomi ialah usaha meningkatkan pendapatan perkapita dengan jalan mengolah kekuatan ekonomi potensial menjadi ekonomi riil melalui penanaman modal, penggunaan teknologi, penambahan pengetahuan, peningkatan ketrampilan, penambahan kemampuan berorganisasi dan manajemen (Sadono Sukirno, 1996: 33). Pembangunan ekonomi yang terus meningkat, tidak hanya dilihat dari aspek kuantitas saja, melainkan yang jauh lebih penting adalah aspek kualitas. Sumber daya yang berkualitas berperan penting dalam proses peningkatan pembangunan ekonomi. Peningkatan kualitas sumber daya manusia akan ditentukan oleh status kesehatan, pendidikan, dan tingkat pendapatan perkapita (Mulyadi, 2003:2-3).

Dalam proses pembangunan tersebut peranan pendidikan amatlah strategis. Pendidikan mampu menciptakan sumber daya manusia yang berkualitas. Pendidikan menjadi salah satu investasi penting dalam pembangunan ekonomi dan merupakan tujuan pembangunan yang mendasar di suatu wilayah. The human capital theory menyatakan bahwa pendidikan menanamkan banyak hal bagi siapa saja yang merasakannya. Hal ini lah yang kemudian memungkinkan mereka mengejar tingkat pendidikan dan pelatihan yang lebih tinggi dan meningkatkan pendapatan masa depan mereka dengan meningkatkan penghasilan seumur hidupnya. (Ghozali, 2000: 60)

Pendidikan adalah variabel yang menentukan kualitas sumber daya manusia suatu bangsa. Maka menjadi tanggung jawab pemerintah untuk dapat menjamin terselenggaranya pendidikan dengan mutu/kualitas yang baik. Bentuk keseriusan pemerintah dan DPR dalam bidang pendidikan tertuang dalam Pasal 31 ayat 4 UUD 1945 Amandemen ke 4 mengamanatkan bahwa negara memprioritaskan anggaran pendidikan sekurang-kurangnya 20 persen dari APBN serta dari APBD untuk memenuhi kebutuhan penyelenggaraan pendidikan nasional.

Proporsi anggaran di Indonesia menurut provinsi yang tertinggi dan terendah untuk setiap provinsi, proporsi anggaran tertinggi yaitu provinsi D.K.I. Jakarta sebesar 18,83 persen dan proporsi 
anggaran terendah yaitu provinsi Papua sebesar 1,35 persen. mengacu pada UUD 1945 pasal 31 ayat 4 tentang besaran anggaran pendidikan 20 persen dari postur APBD dan APBN di Indonesia tidak ada satupun daerah yang telah mencapai 20 persen dari APBD

Hal itu sesuai dengan yang diakatakan Menteri Pendidikan dan Kebudayaan (Mendikbud) Muhajir Effendy mengklaim masih banyak pemerintah daerah yang belum mengalokasikan 20 persen Anggaran Pendapatan dan Belanja Daerah untuk pendidikan. Akibatnya, hampir separuh anggaran pendidikan dari pemerintah pusat terserap untuk pembayaran gaji dan tunjangan sertifikasi.

Menurut UU Sisdiknas No.20/2003, anggaran pendidikan adalah 'Dana pendidikan selain gaji pendidikan dan biaya pendidikan kedinasan dialokasikan minimal 20\% dari APBN pada sektor pendidikan dan minimal 20\% dari APBD." Masalah pendidikan di Indonesia bukan hanya pada tingginya biaya pendidikan untuk mendapat kualitas pendidikan yang baik, tapi juga berhubungan dengan kurangnya sumber daya manusia sebagai pengajar, juga masih banyak pengajar yang memiliki mutu dan kualitas yang belum memadai.

Guru merupakan kunci utama keberhasilan ajar mengajar dalam kelas, jadi apabila kualitas guru kurang baik akan menyebabkan gagalnya proses belajar siswa. Masalah ini dapat diatasi apabila pemerintah lebih baik dalam mengatur anggaran pendidikan, dimulai dari pelatihan peningkatan mutu mengajar, perbaikan kualitas dan kuantitas sekolah, menaikan gaji dan tunjangan guru. Dengan hal ini dapat dipastikan kualitas pendidikan Indonesia dapat lebih maju. Dalam hal lain adalah adanya anggaran pendidikan yang disalahgunakan yang biasanya dilakukan oleh pihak sekolah,baik guru maupun kepala sekolah itu sendiri.

Rasio Guru per murid adalah jumlah guru dibagi dengan jumlah murid tiap jenjang pendidikan. Penggunaan variabel rasio guru per murid untuk menghindari resiko bias dalam pembacaan hasil analisis, karena dalam pendekatan non-parametrik, kinerja yang lebih tinggi secara langsung terkait dengan tingkat input yang lebih tinggi (Afonso dan Aubyn, 2005: 234). Selain itu orang melihat peningkatan kinerja pendidikan biasanya dikaitkan dengan jumlah guru per murid. (Haryadi, 2011: 35-36)

Dengan berlakukannya Undang-undang Nomor 23 Tahun 2014 tentang pemerintahan daerah otonomi daerah adalah hak, wewenang, dan kewajiban daerah otonom untuk mengatur dan mengurus sendiri urusan pemerintahan dan kepentingan masyarakat setempat dalam sistem negara kesatuan republik indonesia, otonomi daerah yang disertai desentralisasi telah memberikan kewenangan kepada urusan pemerintahan oleh pemerintah pusat kepada daerah otonom berdasarkan asas otonomi.

Kebijakan pengelolaan keuangan daerah yang tertuang dalam Peraturan Pemerintah Nomor 58 Tahun 2005, harus mempunyai sasaran yang tepat. Hal ini bertujuan untuk memudahkan identifikasi secara jelas dan terukur mengenai tujuan yang ingin dicapai dalam satu tahun anggaran. Sasaran yang ingin dicapai tersebut tertuang dalam Anggaran Pendapatan dan Belanja Daerah (APBD). Isinya memuat seluruh rencana keuangan yang diperoleh dan digunakan oleh Pemerintah Daerah dalam rangka melaksanakan tugas pemerintahan serta memberikan pelayanan kepada masyarakat.

Belanja yang efisien diyakini dapat mendorong peningkatan kesejahteraan masyarakat secara lebih luas. Jika penggunaannya hemat dan tepat sasaran dikatakan efisiensinya tinggi. Jika terjadi yang sebaliknya, efisiensinya berarti rendah. Efisiensi dapat terjadi ketika dana yang tersedia secara cukup dapat memberikan pelayanan yang optimal sehingga mampu mencapai derajat masyarakat yang baik. Oleh karena itu, belanja yang efisien merupakan isu penting dalam kebijakan sektor publik terutama belanja di bidang pendidikan. 
Berdasarkan latar belakang masalah diatas, penulis tertarik untuk mengadakan penelitian tentang analisis efisiensi pengeluaran pemerintah sektor pendidikan di 34 Provinsi di Indonesia tahun 2017

\section{LANDASAN TEORI}

\section{Teori Pengeluaran Pemerintah}

Pengeluaran pemerintah atau belanja negara, menurut UU No.27 tahun 2014 adalah kewajiban pemerintah pusat yang diakui sebagai pengurangan nilai kekayaan bersih yang terdiri atas belanja Pemerintah Pusat dan Transfer ke Daerah dan Dana Desa.

Fungsi utama negara adalah untuk menyejahterakan setiap anggota masyarakatnya. Untuk itu, pemerintah selalu berupaya memenuhi keinginan serta kebutuhan rakyatnya dengan menyediakan berbagai barang dan jasa yang berbagai bentuk, termasuk uang. penggunaan uang dalam hal inilah yang dimaksud dengan pengeluaran pemerintah (Prasetya, 2012: 1).

Terdapat beberapa ahli yang telah mengungkapkan buah pikirnya tentang pengeluaran pemerintah. Menurut Rostow \& Musgrave dalam Dumairy (1999: 163), pada tahap awal, rasio pengeluaran pemerintah terhadap total pengeluaran nasional relatif besar. Hal ini dikarenakan, pemerintah berinvestasi pada banyak kebutuhan dasar publik yang biasanya merupakan proyek padat modal, seperti pendidikan, kesehatan, serta infrastruktur umum lain seperti listrik, air, juga jalan.

Wagner dalam Dumairy (1999: 162) menyatakan bahwa dalam suatu perekonomian apabila pendapatan perkapita dalam suatu negara meningkat maka pengeluaran pemerintah secara relatif akan meningkat pula. Hal ini karena pemerintah harus turut mengatur berbagai hubungan yang timbul di masyarakat, seperti hukum, pendidikan, rekreasi, kebudayaan, dan lain sebagainya. Dengan kata lain fungsi dan aktivitas pemerintah meningkat pula di berbagai bidang.

Perekonomian memerlukan regulasi atau campur tangan pemerintah untuk mengatur kegiatan ekonomi. Sejalan teori Keynes yang menyatakan bahwa sektor publik sebaiknya turut berperan dalam proses peningkatan perekonomian secara umum. Menurut Keynes, dalam sistem perekonomian, pihak swasta tidak boleh sepenuhnya diberi kewenangan untuk mengelola perekonomian.

Dari sisi ekonomi, pendidikan bukan hanya semata-mata dipandang sebagai kegiatan konsumtif, namun diakui debagai suatu investasi sumberdaya manusia. Pendidikan memberikan sumbangan terhadap pembangunan sosial ekonomi melalui peningkatkan pengetahuan, keterampilan, kecakapan, sikap dan produktivitas. The human capital theory menyatakan bahwa pendidikan menanamkan banyak hal bagi siapa saja yang merasakannya. Hal ini lah yang kemudian memungkinkan mereka mengejar tingkat pendidikan dan pelatihan yang lebih tinggi dan meningkatkan pendapatan masa depan mereka dengan meningkatkan penghasilan seumur hidupnya. (Ghozali, 2000: 60)

\section{Efisiensi}

Nordiawan dan Hertianti (2010:161) menjelaskan bahwa efisiensi adalah hubungan antara barang dan jasa (output) yang dihasilkan sebuah kegiatan/aktivitas dengan sumber daya (input) yang digunakan. Suatu organisasi, program, atau kegiatan dikatakan efisien apabila mampu menghasilkan output tertentu dengan input serendah-rendahnya, atau dengan input tertentu mampu menghasilkan output sebesarbesarnya (spending well).

Dalam beberapa organisasi, efisiensi diukur dengan cara membandingkan biaya aktual dengan standar, dimana biaya-biaya tersebut harus dinyatakan dalam output yang diukur. Pengukuran 
efisiensi secara sederhana dapat dilakukan dengan menggunakan perbandingan antara output yang dihasilkan terhadap input yang digunakan. Proses kegiatan operasional dapat dikatakan efisien apabila suatu produk atau hasil kerja tertentu dapat dicapai dengan menggunakan sumber daya yang paling minimal.

Ada tiga faktor yang menyebabkan efisiensi, yaitu apabila dengan input yang sama menghasilkan output yang lebih besar, dengan input yang lebih kecil menghasilkan output yang sama, dan dengan output yang lebih besar menghasilkan output yang lebih besar. Jika pengertian efisiensi dijelaskan dengan pengertian input-output maka efisiensi merupakan rasio antara output dengan input atau dinyatakan dengan rumus sebagai berikut.

$$
\text { efisiensi: } \frac{\text { Output }}{\text { Input }}
$$

\section{Data Envelopment Analysis (DEA)}

Data Envelopment Analysis (DEA) adalah pemrograman matematika non-parametrik untuk memperkirakan inefisiensi output yang diberikan input dan sebaliknya. Metode ini membangun perbatasan amplop di atas titik data sehingga semua titik yang diamati terletak pada atau di bawah batas produksi (Coelli, 1996: 2). Metode ini, bagaimanapun, tidak menghasilkan hubungan umum dan hanya mengandalkan optimasi rasio input-output.

DEA pertama kali digunakan oleh Farrel pada tahun 1957 untuk membandingkan efisiensi relatif dengan sample petani secara cross section yang terbatas pada satu input dan satu output menjadi multi input dan multi output. DEA kemudian dipopulerkan oleh Charnes, Cooper, dan Rhodes pada tahun 1978. Setelah selang waktu yang cukup lama, DEA dikembangkan kembali oleh Bunker, Charness, dan Cooper pada tahun 1994. Untuk mengakomodasi ketika unit pengambilan keputusan (DMU) beroperasi pada lingkungan skala yang tidak optimal. Skala yang tidak optimal ini mungkin disebabkan oleh kompetisi yang tidak sempurna, kendala sumber daya, dll.

\section{METODE PENELITIAN}

\section{Variabel Penelitian}

Variabel yang digunakan untuk menganalisis efisiensi dalam penelitian ini adalah dengan mengunakan variabel input dan output. Variabel input didefinisikan sebagai sumber daya yang dimanfaatkan oleh unit kegiatan ekonomi (UKE) atau kondisi yang mempengaruhi kinerja dari UKE, sedangkan variabel output adalah keuntungan (benefit) yang dihasilkan sebagai hasil dari kegiatan operasi UKE. Dalam penelitian ini, variabel yang digunakan yaitu anggaran belanja pendidikan sebagai variabel input dan rasio guru murid sebagai variabel output.

\section{Model Analisis}

Metode analisis yang digunakan adalah metode non parametric dengan metode Data Envelopment Analysis (DEA). Dengan DEA dapat diukur efisiensi relatif untuk semua unit yang dianalisis (Ray dan Chen, 2010: 95-97; Cooper, seiford dan Tone, 2002: 12)

Data Envelopment Analysis (DEA) adalah sebuah metode optimasi program matematika yang dipergunakan untuk mengukur efisiensi teknis suatu unit Decision Making Unit (DMU) dan membandingkan secara relative terhadap DMU lain. DEA merupakan suatu teknik pemrograman matematis yang digunakan untuk mengevaluasi efisiensi relatif dari sebuah kumpulan unit-unit pembuat keputusan (DMU) dalam mengelolah sumber daya (input) sehingga menjadi hasil (output) di mana hubungan bentuk fungsi dari input ke output tidak diketahui. 
Haryadi, (2011 :33) mengatakan pilihan VRS dibandingkan Constan Return to Scale (CRS) dengan pertimbangan bahwa tidak semua unit pengambilang keputusan (DMU) beroperasi pada skala optimal dan dikareanakan tidak ada kompetisi. Selain asumsi VRS, digunakan dua pendekatan untuk mengukur efisiensi: pendekatan input oriented (minimiasi input) dan pendekatan output oriented. Estimasi untuk memaksimumkan output digunakan pada tahap efisensi teknis sistem. Sedangkan pada efisiensi tenkis biaya dengan penggunaan indikator intermediate output yang bersifat rasio batasan yang bersifat relatif, maka pada tahap efisiensi teknis biaya digunakanlah orientasi dengan minimisasi input.

Berdasarkan hubungan skala antara variabel input dan output, pengukuran efisiensi dalam penelitian ini akan dilakukan dengan pendekatan variable return to scale (VRS) dengan pendekatan input oriented. Metode penelitian ini melibatkan input pendidikan di Indonesia sedangkan output yaitu rasio guru/murid. Metode Delta Envelopment Analysis saat mengevaluasi efisiensi rasionya tidak akan lebih dari 1 , yang berarti 1 adalah keadaan dimana suatu unit kegiatan telah mencapai kondisi efisien.

\section{HASIL DAN PEMBAHASAN}

Nilai efisiensi anggaran belanja pendidikan pemerintah daerah di Indonesia diperoleh dengan menggunakan variabel input berupa nominal jumlah belanja pendidikan yang dikeluarkan masingmasing pemerintah daerah provinsi. Adapun variabel output yang digunakan untuk menghitung nilai efisiensi biaya adalah rasio guru per murid. Asumsi yang digunakan adalah bahwa besarnya input belanja pendidikan yang dikeluarkan pemerintah daerah mampu menghasilkan jumlah output fasilitas dan layanan pendidikan dengan besaran yang tidak sama. Perhitungan efisiensi teknis biaya ini menggunakan asumsi Variabel Ruturn to Scale (VRS) dan model orientasi input (input oriented).

Tabel 1 Nilai Efisiensi Biaya Anggaran Belanja Pendidikan Per Provinsi di Indonesia Tahun 2017

\section{Nama Wilayah}

Prov. Maluku, Prov. Gorontalo, Prov. Aceh

Prov. Sulawesi Barat, Prov. Maluku Utara, Prov. Bangka Belitung, Prov.

Kalimantan Tengah, Prov. Bengkulu, Prov. Kalimantan Utara

\section{Nilai}

Efisiensi

1,000

$0,617-0,929$

$0,332-0,547$

Sulawesi Tengah, Prov. Jambi, Prov. Nusa Tenggara Timur, Prov. Nusa

Tenggara Barat, Prov. Kalimantan Barat, Prov. D.I. Yogyakarta, Prov. Sumatera

Barat, Prov. Kalimantan Selatan

Prov. Bali, Prov. Lampung, Prov. Sumatera Selatan, Prov. Papua Barat, Prov.

Kalimantan Timur, Prov. Sulawesi Selatan, Prov. Banten, Prov. Riau, Prov.

$0,122-0,276$

Sumatera Utara, Prov. Papua

Prov. Jawa Tengah, Prov. Jawa Timur, Prov. Jawa Barat, Prov. D.K.I. Jakarta

Sumber : Data Envelopment Analysis (Data Diolah)

Berdasarkan Tabel 1, dari 34 provinsi yang ada di Indonesia menunjukkan hasil analisis efisiensi biaya anggaran belanja pendidikan pemerintah daerah dengan menggunakan DEA tahun 2017. Hasil penelitian ini menunjukkan kondisi pencapaian efisiensi biaya anggaran belanja pendidikan terdapat hanya 3 provinsi yang mencapai efisiensi dari keseluruhan 34 provinsi di Indonesia jika dipersentasekan yaitu sebesar 8,82 persen, sedangkan untuk provinsi dengan tingkat efisien 
terendah 0,029 ini menunjukkan masih sangat sedikit sekali provinsi yang mencapai tingkat efisien.

Pada penelitian ini, berdasarkan hasil penghitungan menggunakan Data Envelopment Analysis antara Alokasi Anggaran Belanja Pendidikan dan Rasio Guru Murid setiap provinsi di Indonesia pada tahun 2017, diperoleh hasil dari 34 provinsi hanya terdapat 3 provinsi yang mencapai efisiensi yaitu provinsi Maluku, provinsi Gorontalo, provinsi Aceh. Jika dipersentasekan untuk keseluruhan yaitu sebesar 8,82 persen ini menunjukkan masih sangat sedikit sekali provinsi yang mencapai tingkat efisien.

Hal ini bahwa secara teknis biaya masih banyak daerah yang belum mencapai tingkat efisien provinsi di Indonesia dan belum ada satupun daerah yang mengalokasikan anggaran belanja telah sesuai dengan amanat UUD 1945. Secara keseluruhan masih banyak daerah yang belum mencapai efisiensi 1,000. Dengan demikian di dalam perhitungan target perbaikan input dan output untuk seluruh provinsi sangat perlu perbaikan sesuai target yang harus dirubah. Adapun secara umum perbaikan yang dapat dilakukan terkait dengan provinsi yang masih belum efisien yaitu melakukan evaluasi terhadap alokasi belanja di sektor pendidikan sehingga tidak terjadi pemborosan dan segera melakukan perbaikan.

hasil penelitian menggunakan Data Envelopment Analysis untuk provinsi di Indonesia yang belum mencapai tingkat efisien yaitu dengan mengurangi jumlah alokasi anggaran belanja pendidikan yang diberikan untuk setiap daerah agar sesuai dengan kondisi rasio guru murid yang ada disetiap daerah tersebut. Untuk alokasi anggaran belanja pendidikan, berdasarkan hasil penghitungan menggunakan Data Envleopment Analysis besaran alokasi anggaran belanja pendidikan yang harus diberikan sebagai berikut:

1. Daerah yang mencapai efisiensi nilai 0,617 - 0,929 yaitu Prov. Sulawesi Barat, Prov. Maluku Utara, Prov. Bangka Belitung, Prov. Kalimantan Tengah, Prov. Bengkulu, Prov. Kalimantan Utara dalam hal ini pemerintah setidaknya harus mengurangi anggaran yang diberikan yaitu sebesar 141.470 juta - 1.142.800 milyar agar daerah tersebut mencapai tingkat eifisien.

2. Daerah yang mencapai efisiensi nilai 0,332 - 0,547 yaitu Prov. Kepulauan Riau, Prov. Sulawesi Utara, Prov. Sulawesi Tenggara, Prov. Sulawesi Tengah, Prov. Jambi, Prov. Nusa Tenggara Timur, Prov. Nusa Tenggara Barat, Prov. Kalimantan Barat, Prov. D.I. Yogyakarta, Prov. Sumatera Barat, Prov. Kalimantan Selatan dalam hal ini pemerintah setidaknya harus mengurangi anggaran yang diberikan yaitu sebesar 1.521.370 - 3.693.030 milyar agar daerah tersebut mencapai tingkat eifisien

3. Daerah yang mencapai efisiensi nilai 0,122 - 0,276 yaitu Prov. Bali, Prov. Lampung, Prov. Sumatera Selatan, Prov. Papua Barat, Prov. Kalimantan Timur, Prov. Sulawesi Selatan, Prov. Banten, Prov. Riau, Prov. Sumatera Utara, Prov. Papua dalam hal ini pemerintah setidaknya harus mengurangi anggaran yang diberikan yaitu sebesar 4.814.780 - 13.244.350 milyar agar daerah tersebut mencapai tingkat eifisien

4. Daerah yang mencapai efisiensi nilai 0,029 - 0,079 yaitu Prov. Jawa Tengah, Prov. Jawa Timur, Prov. Jawa Barat, Prov. D.K.I. Jakarta dalam hal ini pemerintah setidaknya harus mengurangi anggaran yang diberikan yaitu sebesar 21.523.990 - 61.772.770 milyar agar daerah tersebut mencapai tingkat eifisien

\section{KESIMPULAN}

Berdasarkan hasil dan pembahasan yang dilakukan mengenai Analisis Efisiensi Pengeluaran Pemerintah di Indonesia Studi Kasus bidang Pendidikan tahun 2017 dengan menggunakan metode 
Data Envelopment Analysis (DEA), maka dapat disimpulkan kondisi pencapai efisiensi biaya anggaran belanja pendidikan dari 34 provinsi di Indonesia hanya terdapat 3 provinsi yang mencapai tingkat efisien. Jika dipersentasekan untuk keseluruhan yaitu sebesar 8,82 persen yaitu provovinsi Maluku, provinsi Gorontalo dan provinsi Aceh, ini menunjukkan masih sangat sedikit provinsi yang mencapai tingkat efisiensi.

Berdasarkan hasil analisis penghitungan alokasi anggaran belanja pendidikan dan rasio guru murid menggunakan Data Envelopment Analysis dalam penelitian ini, maka saran yang dapat diajukan yaitu pemerintah daerah yang belum efisien yaitu melakukan evaluasi terhadap penggunaan anggaran belanja pendidikan yang mana harus disesuaikan dengan jumlah rasio guru dan murid yang ada di setiap daerah sehingga tidak terjadi pemborosan dan pemerintah daerah segera melakukan perbaikan.

Rekomendasi untuk Penelitian Lanjutan yang diberikan berdasarkan hasil penelitian ini adalah, peneliti selanjutnya agar menambahkan variabel-variabel yang sebelumnya tidak digunakan dalam penelitian ini serta menggunakan data penelitian yang lebih lama (time series) untuk melihat kecenderungan dari data, sehingga dapat menghasilkan analisis penelitian yang lebih ditail.

\section{DAFTAR PUSTAKA}

Afonso, Antonio and Miguel St. Aubyn. 2005. Non-parametric Approaches to Education and Health Efficiency in OECD Countries. Journal of Apllied Economics, 3. (2): 175-185.

Coelli, T. J., 1996. A Guide to DEAP Version 2.1: A Data Envelopment Analysis (Computer) Program. CEPA Working Papers No.8, Department of Econometrics, University of New England

Cooper William. Lawrence M Seiford and Joe Zhu. Chapter 1 : Data Envelopment Analysis: Histor, Models and Interpretations

Dumairy. 1999. Perekonomian Indonesia. Yogyakarta: Erlangga.

Ghozali, A. 2000. Pendidikan: Antara Investasi manusia dan Alat Deskriminasi. Jurnal Pendidikan dan Kebudayaan. 23 (V): 57-85.

Haryadi, Arinto. 2011. Analisis Efisiensi Teknis Bidang Pendidikan (Penerapan Data Envelopment Analysis). Jakarta: Program Magister Perencanaan dan Kebijakan Publik Unversitas Indonesia

Mangkoesobroto, G. 1993. Ekonomi Publik Edisi III. Yogyakarta: BPFE.

Mardiasmo. 2002. Akutansi Sektor Publik, Andi: Yogyakarta

Mills, A. dan Gilson, L (terj). 1990. Ekonomi Kesehatan untuk Negara-Negara Berkembang. Jakarta. Dian Rakyat, Jakarta.

Mulyadi. 2003. Ekonomi Sumber Daya Manusia dalam Perpsektif Pembangunan. Jakarta : PT Raja Grafindo Persada.

Nordiawan, Deddi, dan Ayuningtyas Hertianti. 2010. Akuntansi Sektor Publik. Jakarta: Salemba Empat.

Nurkolis. 2002. Pendidikan Sebagai Investasi Jangka Panjang. (Online) https://www.scribd.com/doc/200585703/Artikel-Pendidikan-Sebagai- Investasi-

Jangka-Panjang 
Pemerintah Indonesia. 2003. Undang-Undang No. 20 Tahun 2003 tentang Sistem Pendidikan Nasional. Lembaran RI Tahun 2003, No. 20. Jakarta : Sekretariat Jakarta

Prasetya, F. (2012). Modul Ekonomi Publik: Teori Pengeluaran Pemerintah. Malang: Universitas Brawijaya.

Prasetyo, Ahmad Danu and Ubaidillah Zuhdi. (2013). The Government Expenditure Efficiency towards the Human Development. Procedia Economics and Finance (5), Hal. 615 - 622

Pratama, Zulfahmi, dkk. 2016. Analisis Efisiensi Pengeluaran Pemerintah Daerah di Provinsi Jawa Timur dengan Pendekatan Data Envelopment Analysis (DEA). Jember: Jurusan Ilmu Ekonomi dan Studi Pembangunan, Universitas Jember

Rapiuddin dan Bahrul Ulum Rusydi. 2017. Efisiensi Belanja Pemerintah di Sektor Pendidikan dan Kesehatan di Provinsi Sulawesi Selatan. EcceS Vol.4, No.1, Hal.23-39.

Sukirno, Sadono. 1996. Pengantar Teori Makro Ekonomi. Jakarta. PT Raja Grafindo Persada.

Sukirno, Sadono. 2006. Pengantar Teori Mikro Ekonomi. Jakarta : PT. Raja Grafindo Persada.

Tjiptoherijanto dan Soesetyo. 1994. Ekonomi Kesehatan. Jakarta: PT Rineka Cipta.

World Bank, 2007, Kajian Pengeluaran Publik Indonesia : Memaksimalkan Peluang Baru. Jakarta 